Jurnal Profesional Fisioterapi

E-ISSN: XXXX-XXXX |P-ISSN: XXXX-XXXX

Vol 1 No 1, Januari (2022)

\title{
KOMORBIDITAS PENYANDANG CEREBRAL PALSY DI KOMUNITAS CEREBRAL PALSY METRO
}

\author{
Al Um Aniswatun Khasanah', Efraldo Yudistira², Bota Muhammad Akbar ${ }^{3}$, \\ Anak Ayu Nyoman Trisna Nata Dewi ${ }^{4}$
}

\author{
${ }^{1}$ Program Studi DIII Fisioterapi, Universitas Muhammadiyah Metro, Metro, Lampung \\ 2,3 Program Studi DIII Fisioterapi, Universitas Muhammadiyah Metro, Metro, Lampung \\ ${ }^{4}$ Departemen Fisioterapi,Universitas Udayana, Denpasar, Bali \\ anisfisioterapi@gmail.com
}

\begin{abstract}
ABSTRAK
Kondisi salah satu difabel macam-macam salah satunya yaitu Cerebral Palsy. Sebagian besar anak Cerebral Palsy paling sedikit memiliki satu kelainan penyerta atau komorbiditas. Pada data SCPE, komorbiditas yang paling umum ditemukan adalah gangguan berbahasa (71\%), diikuti oleh gangguan intelektual (62\%), epilepsi (39\%), dan gangguan penglihatan (22\%) Tujuan untuk mengetahui masalah komorbiditas Cerebral Palsy sehubungan dengan angka harapan hidup pasien yang bergantung pada beratnya disabilitas yang dialami pada komunitas Cerebral Palsy Metro.Rancangan Penelitian ini merupakan penelitian deskriptif analitik dengan menggunakan desain cross sectional atau potong lintang. Dalam desain cross sectional digunakan pendekatan transversal, dimana observasi terhadap variabel bebas dan variabel terikat dilakukan hanya sekali pada saat yang sama.Dengan Jumlah sampel penelitian 50. Subjek penelitian laki-laki $31(62 \%)$ dan perempuan $19(38 \%)$, dengan sampel rentang usia antara 0-18 tahun. Peserta paling banyak pada tipe CP Spastik Quadriplegia. hasil Komorbiditas Cerebral Palsy pada subjek penelitian. Pada Disabilitas intelektual berjumlah 30 (60\%), Epilepsy berjumlah 19(38\%), Gangguan visual 3(6\%), Gangguan wicara 37(74\%), Gangguan perkembangan dan pertumbuhan 14(28\%), Gangguan BAB 10 (20\%), Gangguan Pernapasan 4 (8\%), Gangguan ortopedi deformitas ankle 23(46\%), Gangguan deformitas scoliosis 21 (42\%), Gangguan subluksasi Hip 9(18\%), Gangguan tidur 11 (22\%), yang mana perindividu Cerebral Palsy paling banyak memiliki tiga komorbiditas dan banyak dimiliki oleh tipe CP Spastik Quadriplegia. Komorbiditas pada penyandang cerebral palsy di komunitas cerebral palsy metro yang paling banyak pada gangguan wicara serta ditemukan lebih dari tiga komorbiditas pada individu cerebral palsy dengan tipe CP spastik Quadriplegia.
\end{abstract}

Kata Kunci: komorbiditas, cerebral palsy, komunitas cerebral palsy metro

\section{Comorbidities Cerebral Palsy in Community Metro Cerebral Palsy}

\begin{abstract}
The condition of one of the disabled people is various, one of which is Cerebral Palsy. Most children with Cerebral Palsy have at least one comorbid disorder or comorbidity. In the SCPE data, the most common comorbidities found were language disorders (71\%), followed by intellectual disorders (62\%), epilepsy (39\%), and visual disturbances $(22 \%)$. The survival of patients who depend on the severity of disability experienced in the Cerebral Palsy Metro community. Design This study is a descriptive analytic study using a cross sectional or cross-sectional design. In the cross sectional design used a transverse approach, where observations of the independent variable and the dependent variable were carried out only once at the same time. With a total sample of 50 . The research subjects were 31 men (62\%) and 19 women (38\%), with a sample of age range between $0-18$ years. Most participants were in the type of Spastic Quadriplegia CP. Outcomes of Comorbid Cerebral Palsy in study subjects. Intellectual disability is $30(60 \%)$, Epilepsy is $19(38 \%)$, Visual impairment is 3(6\%), Speech disorder is 37(74\%), Development and growth disorders is $14(28 \%)$, Defecation disorders 10 (20\%), Respiratory Disorders 4 (8\%), Orthopedic disorders Ankle deformities $23(46 \%)$, Scoliosis deformity disorders 21 (42\%), Hip subluxation disorders $9(18 \%)$, Sleep disturbances 11 $(22 \%)$, which were individual Cerebral Palsy has at most three comorbidities and is mostly owned by the Spastic Quadriplegia CP type. Comorbidities in people with cerebral palsy in the metro cerebral palsy community were the most common in speech disorders and more than three comorbidities were found in cerebral palsy individuals with the type of spastic Quadriplegia CP.

Keyword: Comorbidities,Cerebral Palsy, Community Metro Cerebral Palsy
\end{abstract}

\section{PENDAHULUAN}

Kondisi salah satu difabel macam-macam salah satunya yaitu Cerebral Palsy. Secara global, prevalensi cerebral palsy berkisar antara 1,5-4 kasus per 1000 kelahiran hidup. Cerebral palsy lebih umum terjadi pada laki-laki dibandingkan perempuan. Tipe cerebral palsy yang paling banyak ditemukan adalah tipe spastik (77,4\%). Di Amerika 
Jurnal Profesional Fisioterapi

E-ISSN: XXXX-XXXX | P-ISSN: XXXX-XXXX

Vol 1 No 1, Januari (2022)

Serikat, sebanyak $41 \%$ anak dengan cerebral palsy juga memiliki komorbiditas epilepsi, dan $6,9 \%$ memiliki autism spectrum disorder (ASD). ${ }^{1}$ Data epidemiologi cerebral palsy di Indonesia menunjukkan data Riset Kesehatan Dasar Republik Indonesia tahun 2010 mencatat persentase anak usia 24-59 bulan yang mengalami cerebral palsy sebesar $0,09 \% .^{2}$

Sebagian besar anak Cerebral Palsy paling sedikit memiliki satu kelainan penyerta atau komorbiditas. ${ }^{3}$ Komorbiditas merupakan suatu kondisi terjadinya dua atau lebih gangguan pada suatu individu dan dapat memperberat kondisi yang ada, pada data SCPE, komorbiditas yang paling umum ditemukan adalah gangguan berbahasa $(71 \%)$, diikuti oleh gangguan intelektual (62\%), epilepsi $(39 \%)$, dan gangguan penglihatan $(22 \%)$. Gangguan pendengaran merupakan komplikasi paling umum yang memperburuk gangguan berbahasa. Berbagai komorbiditas yang sering menyertai anak Cerebral Palsy berdampak negatif terhadap kualitas hidup anak tersebut juga keluarga dan masyarakat. ${ }^{4}$ Tingkat keparahan dan prognosis Cerebral Palsy bergantung pada bentuk klinis dan adanya komorbiditas yang terkait, walaupun tidak ada penanganan khusus untuk kerusakan otak yang menyebabkan disfungsi motorik pada Cerebral Palsy, intervensi klinis yang berfokus pada pengurangan komorbiditas Cerebral Palsy bisa berdampak positif pada kualitas hidup para penyandang Cerebral Palsy. ${ }^{5}$

Untuk Di Lampung sendiri khususnya didaerah kota Metro pada Komunitas Cerebral Palsy Metro telah banyak kasus Cerebral Palsy yang menjadi anggota komunitas dari anak-anak hingga remaja sekitar 100 anggota namun untuk masalah komorbiditasnya belum terdata. Maka dari itu peneliti sangat tertarik untuk mengetahui masalah komorbiditas Cerebral Palsy sehubungan dengan angka harapan hidup pasien yang bergantung pada beratnya disabilitas yang dialami. Komorbiditas pada anak cerebral palsy salah satunya masalah dengan gangguan respirasi yang bisa berkaitan dengan mortalitas. Mortalitas meningkat seiring dengan peningkatan variasi dan tingkat disabilitas. Pada penelitian di Australia, penyebab mortalitas utama adalah gangguan respirasi (58,6\%), terutama pneumonia (82\%). Mortalitas pada pasien dengan disabilitas yang berat adalah $20 \%$ pada usia 4 tahun. ${ }^{6}$

\section{METODE}

Rancangan Penelitian ini merupakan penelitian deskriptif analitik dengan menggunakan desain cross sectional atau potong lintang. Dalam desain cross sectional digunakan pendekatan transversal, dimana observasi terhadap variabel bebas dan variabel terikat dilakukan hanya sekali pada saat yang sama. ${ }^{7}$ Sampel penelitian anak dengan kondisi penyandang Cerebral Palsy yang didampingi bersama orang tuanya. Penelitian dilakukan di bulan Juni 2021 dengan jumlah anggota 50 anak yang memenuhi kriteria inklusi penyandang Cerebral Palsy yang didampingi bersama orang tuanya dan menjadi anggota Komunitas Cerebral Palsy Kota Metro dengan kriteria ekslusi menolak menjadi subjek penelitian, tidak mengisi kuis respondensi dan masuk RS.

\section{HASIL}

Tabel 1. Karakteristik Umum

\begin{tabular}{lcc}
\hline \multicolumn{1}{c}{ variable } & Jumlah $(\mathrm{n})$ & Presentasi (\%) \\
\hline Jenis Kelamin & & \\
Laki-laki & 31 & $62 \%$ \\
Perempuan & 19 & $38 \%$ \\
Usia (tahun) & & $42 \%$ \\
$0-6$ & 21 & $50 \%$ \\
$6-12$ & 25 & $8 \%$ \\
$12-18$ & 4 & \\
\hline
\end{tabular}

Tabel 1. Menunjukkan hasil karakteristik umum dari subjek penelitian berdasarkan jenis kelamin dan usia. Jumlah laki-laki lebih banyak daripada perempuan yaitu laki-laki berjumlah $31(62 \%)$ sedangkan perempuan berjumlah 19 (38\%). Subjek Penelitian berdasarkan usia yang paling banyak pada penelitian ini dengan rentang usia 0-12 tahun, untuk usia 0-6 tahun berjumlah 21 (42\%), usia 6-12 tahun berjumlah 25 (50\%), usia 12-18 tahun berjumlah 4 (8\%).

Tabel 2. Klasifikasi Cerebral Palsy

\begin{tabular}{lcc}
\hline \multicolumn{1}{c}{ variable } & Jumlah $(\mathrm{n})$ & Presentasi $(\%)$ \\
\hline Tipe CP (Cerebral Palsy) & 22 & $44 \%$ \\
CP Spastik Quadriplegia & 19 & $38 \%$ \\
CP Spastik Diplegia & 6 & $12 \%$ \\
CP Flacid Diplegia & &
\end{tabular}


Jurnal Profesional Fisioterapi

E-ISSN: XXXX-XXXX | P-ISSN: XXXX-XXXX

Vol 1 No 1, Januari (2022)

CP Athetoid

2

$4 \%$

CP Hemiplegia

1

$2 \%$

Tabel 2. Menunjukkan hasil Klasifikasi jumlah Tipe Cerebral Palsy (CP) pada subjek penelitian ini. Pada tipe CP Spastik Quadriplegia berjumlah 22 (44\%), CP Spastik diplegia berjumlah 19 (38\%), CP Flacid Diplegia berjumlah 6 (12\%), CP berjumlah Athetoid 2 (4\%), CP Hemiplegia berjumlah 1 (2\%).

Tabel 3. Komorbiditas Cerebral Palsy

\begin{tabular}{lcc}
\multicolumn{1}{c}{ variable } & Jumlah $(\mathrm{n})$ & Presentasi (\%) \\
\hline Disabilitas intelektual & 30 & $60 \%$ \\
Epilepsy & 19 & $38 \%$ \\
Gangguan visual & 3 & $6 \%$ \\
Gangguan wicara & 37 & $74 \%$ \\
Gangguan perkembangan & 14 & $28 \%$ \\
pertumbuhan & & \\
Gangguan BAB & 10 & $20 \%$ \\
Gangguan Pernapasan & 4 & $8 \%$ \\
Gangguan ortopedi deformitas ankle & 23 & $46 \%$ \\
Gangguan deformitas scoliosis, & 21 & $42 \%$ \\
Gangguan subluksasi Hip & 9 & $18 \%$ \\
Gangguan tidur & 11 & $22 \%$ \\
\hline
\end{tabular}

Tabel 3. Menunjukkan hasil Komorbiditas Cerebral Palsy pada subjek penelitian. Pada Disabilitas intelektual berjumlah $30(60 \%)$, Epilepsy berjumlah 19(38\%), Gangguan visual 3(6\%), Gangguan wicara 37(74\%), Gangguan perkembangan dan pertumbuhan 14(28\%), Gangguan BAB 10 (20\%), Gangguan Pernapasan 4 $(8 \%)$, Gangguan ortopedi deformitas ankle 23(46\%), Gangguan deformitas scoliosis 21 (42\%), Gangguan subluksasi Hip 9(18\%), Gangguan tidur 11 (22\%).

Tabel 4. Banyaknya komorbiditas Cerebral Palsy berdasarkan jumlah komorbiditas

\begin{tabular}{lcc}
\hline \multicolumn{1}{c}{ variable } & Jumlah $(\mathrm{n})$ & Presentasi (\%) \\
\hline Satu Komorbiditas & 2 & $4 \%$ \\
Dua Komorbiditas & 12 & $24 \%$ \\
Tiga Komorbiditas & 13 & $26 \%$ \\
Lebih dari Tiga Komorbiditas & 23 & $46 \%$ \\
\hline
\end{tabular}

Tabel 4 Menunjukkan hasil dari banyaknya komorbiditas pada Cerebral Palsy berdasarakan jumlah komorbiditas. Untuk yang memiliki satu komorbiditas pada subjek penelitian ini berjumlah 2 (4\%), dua komorbiditas berjumlah 12 (24\%), tiga komorbiditas berjumlah 13 (26\%) dan lebih dari tiga komorbiditas berjumlah 23 $(46 \%)$.

Tabel 5. Banyaknya Komorbiditas berdasarkan Tipe Cerebral Palsy

\begin{tabular}{lcc}
\hline \multicolumn{1}{c}{ variable } & Jumlah (n) & Presentas \\
\hline CP Spastik Quadriplegia & & \\
Satu Komorbiditas & 0 & 0 \\
Dua Komorbiditas & 0 & $10 \%$ \\
Tiga Komorbiditas & 5 & $34 \%$ \\
Lebih dari Tiga Komorbiditas & 17 & $2 \%$ \\
CP Spastik Diplegia & 1 & $20 \%$ \\
Satu Komorbiditas & 10 & $10 \%$ \\
Dua Komorbiditas & 5 & $6 \%$ \\
Tiga Komorbiditas & 3 & \\
Lebih dari Tiga Komorbiditas & & 0 \\
CP Flacid Diplegia & 0 & $4 \%$ \\
Satu Komorbiditas & 2 & $4 \%$ \\
Dua Komorbiditas & 2 & \\
Tiga Komorbiditas & 2 & 0 \\
Lebih dari Tiga Komorbiditas & & 0 \\
CP Athetoid & 0 &
\end{tabular}


Jurnal Profesional Fisioterapi

E-ISSN: XXXX-XXXX | P-ISSN: XXXX-XXXX

Vol 1 No 1, Januari (2022)

Tiga Komorbiditas

Lebih dari Tiga Komorbiditas

CP Hemiplegia

Satu Komorbiditas

Dua Komorbiditas

Tiga Komorbiditas

Lebih dari Tiga Komorbiditas

$\begin{array}{lc}1 & 2 \% \\ 1 & 2 \% \\ 1 & 2 \% \\ 0 & 0 \\ 0 & 0 \\ 0 & 0\end{array}$

Tabel 5 Menunjukkan banyaknya jumlah komorbiditas berdasarkan tipe Cerebral Palsy. Pada Tipe CP Spastik Quadriplegia untuk tiga komorbiditas berjumlah $5(10 \%)$ dan untuk lebih dari tiga komorbiditas berjumlah 17 (34\%), untuk tipe CP Spastik Diplegia satu komorbiditas berjumlah 1 (2\%), dua komorbiditas berjumlah 10 (20\%), tiga komorbiditas, lebih dari tiga komorbiditas berjumlah $3(6 \%)$, untuk tipe CP Falcid Diplegia pada dua komorbiditas berjumlah $2(4 \%)$, tiga komorbiditas berjumlah 2 (4\%), lebih dari tiga komorbiditas berjumlah 2 (4\%), untuk tipe CP Athetoid pada tiga komorbiditas berjumlah $1(2 \%)$ dan lebih dari tiga komorbiditas berjumlah 1 (2\%), untuk tipe CP Hemiplegia hanya ada satu komorbiditas dengan jumlah 1 (2\%).

\section{DISKUSI}

Pada subjek penelitian untuk karakteristik sampel penelitian penderita Cerebral Palsy jumlah laki-lakinya 31 (62\%) lebih banyak dibandingkan perempuan 19 (38\%), beberapa penelitian menyatakan bahwa jumlah Cerebral Palsy pada laki-laki lebih tinggi daripada perempuan. ${ }^{8}$ Penelitian pada anak Cerebral Palsy yang dilakukan di sekolah luar biasa di Bandung sejumlah 43 anak yaitu 22 laki-laki dan 21 anak perempuan. ${ }^{9}$

Berdasarkan usia pada sampel penelitian ini yang mengikuti komunitas banyak terdapat rentang usia 0-6 thn sejumlah 21 (42\%) untuk rentang usia 7-12 tahun 25 (50\%) , 13-18 tahun hanya 4 (8\%). Pada penelitian ini diperoleh data usia yang mengikuti komunitas cerebral palsy kota Metro terbanyak antara usia 0-12 tahun, para orangtua mengikuti komunitas ini guna menjalin silaturahmi, memperoleh shareing dan ilmu tentang kondisi anak cerebral palsy. Peneliti membagi rentang usia untuk membedakan usia antara anak balita, anak-anak dan remaja.

Pada Subjek penelitian tipe klasifikasi cerebral palsy diperoleh hasil pada tipe CP Spastik Quadriplegia berjumlah 22 (44\%) lebih banyak dibandingkan CP Spastik diplegia berjumlah 19 (38\%), CP Flacid Diplegia berjumlah 6 (12\%), CP berjumlah Athetoid 2 (4\%)dan untuk CP Hemiplegia hanya 1 (2\%). Demikian juga dengan penelitian Gabis dkk yang menyebutkan dalam penelitiannya terdapat $62,4 \%$ kasus Quadriplegia, $15 \%$ diplegia, $12 \%$ hemiplegia, dan $11 \%$ diskinetik. ${ }^{10}$ Bahwa spastik tetraplegia lebih sering terjadi pada bayi baru lahir dengan usia kehamilan cukup bulan dengan cedera hipoksik-iskemik.$^{11}$

Hasil dari data penelitian ini untuk Komorbiditas Cerebral Palsy pada subjek disabilitas intelektual berjumlah 30 (60\%) dan Epilepsy berjumlah 19(38\%). Gangguan visual 3(6\%), Gangguan wicara 37(74\%), Gangguan perkembangan dan pertumbuhan 14(28\%), Gangguan BAB 10 (20\%), Gangguan Pernapasan 4 (8\%), Gangguan ortopedi deformitas ankle 23(46\%), Gangguan deformitas scoliosis 21 (42\%), Gangguan subluksasi Hip 9(18\%), Gangguan tidur 11 (22\%). Komorbiditas pada penelitian lain juga menunjukkan yaitu disabilitas intelektual (47.7\%) Epilepsi (41.6\%), Gangguan wicara (27,7\%) dan Gangguan visual (10\%). ${ }^{12}$ Penelitian yang lain menunjukkan Gangguan perkembangan dan pertumbuhan (33.6\%), Gangguan BAB pada penelitiannya menunjukkan 3 dari 5 anak Cerebral Palsy mengalami masalah BAB (39,1\%), Gangguan Pernapasan (29,7\%), Gangguan ortopedi deformitas ankle (15,6\%), Gangguan deformitas scoliosis (15\%), Gangguan subluksasi Hip (0,9\%), Gangguan tidur (8,3\%). ${ }^{13}$

Sejumlah 23 anak pada penelitian ini memiliki lebih dari tiga komorbiditas, pada penelitian lain juga menunjukkan bahwa setidaknya sebanyak 52 \% anak Cerebral Palsy setidaknya memiliki tiga kategori komorbiditas berdasarkan penyebabnya, komplikasinya dan kejadiannya. ${ }^{13}$

Hasil dari penelitian pada Tipe CP Spastik Quadriplegia menunjukkan jumlah terbanyak pada lebih dari tiga komorbiditas berjumlah 17 (34\%),untuk tipe CP Spastik Diplegia terbanyak dua komorbiditas berjumlah 10 (20\%), dan untuk tipe CP Falcid Diplegia pada dua komorbiditas berjumlah 2 (4\%), tiga komorbiditas berjumlah 2 (4\%), lebih dari tiga komorbiditas berjumlah 2 (4\%), untuk tipe CP Athetoid pada tiga komorbiditas berjumlah 1 (2\%) dan lebih dari tiga komorbiditas berjumlah $1(2 \%)$, untuk tipe CP Hemiplegia hanya ada satu komorbiditas dengan jumlah 1 $(2 \%)$.Tipe CP spastik tetraplegia memiliki komorbiditas lebih dari tiga paling banyak diantara tipe lainnya yaitu sebanyak 10 (23,26\%) pada spastik tetraplegia. Banyaknya komorbiditas yang ada pada anak CP menunjukkan tingkat keparahan dan prognosis dari anak tersebut. ${ }^{14}$ penelitian lain juga menyebutkan pada CP Spastik $70 \%$ mengalami masalah bicara $85 \%$, kesulitan makan $86 \%$, gangguan menelan $77 \%$, disabilitas inttelektual $88 \%$, gangguan aktifitas $62 \%$, gangguan visual $54 \%$, gangguan berkomunikasi $45 \%$, epilepsy $35 \%$, gangguan pendengaran $12 \%$ dan masalah nutrisi $51 \%{ }^{15}$

\section{SIMPULAN}

Komorbiditas pada penyandang cerebral palsy di komunitas cerebral palsy metro yang paling banyak pada gangguan wicara serta ditemukan lebih dari tiga komorbiditas pada individu cerebral palsy dengan tipe CP spastik Quadriplegia. 
Jurnal Profesional Fisioterapi

E-ISSN: XXXX-XXXX | P-ISSN: XXXX-XXXX

Vol 1 No 1, Januari (2022)

\section{DAFTAR PUSTAKA}

1 Michelsen, S. I., Flachs, E. M., Damsgaard, M. T., Parkes, J., Parkinson, K., Rapp, M., Arnaud, C., Nystrand, M., Colver, A., Fauconnier, J., Dickinson, H. O., Marcelli, M., Uldall, P.(2014) European study of frequency of participation of adolescents with and without cerebral palsy, European Journal of Paediatric Neurology, 18, 282-94, 2014

[PubMed] [Reference list]

2 Kementrian Kesehatan Republik Indonesia. Riset Kesehatan Dasar. 2010. Available from:

http://kesga.kemkes.go.id/images/pedoman/Riskesdas\%202010\%20Nasional.pdf

3 CDC. Data and Statistics for Cerebral Palsy. Centers for Disease Control and Prevention. 2020 [cited 18 July 2020]. Available from: https://www.cdc.gov/ncbddd/cp/data.html

4 Gabis, L. V., Tsubary, N. M., Leon, O., Ashkenasi, A., \& Shefer, S. (2015). Assessment of Abilities and Comorbidities in Children With Cerebral Palsy. Journal of Child Neurology, 30(12), 1640-1645.

5 Tessier, D. W., Hefner, J. L., \& Newmeyer, A. (2014). Factors Related to Psychosocial Quality of Life for Children with Cerebral Palsy. International Journal of Pediatrics, 2014, 1-6.

6 S. Goldsmith, S., Hutton, J., E. Blair, L., et al. Survival and mortality in cerebral palsy: Observations to the sixth decade from a data linkage study of a total population register and National Death Index. BMC Neurology. 2020.

Available from: https://bmcneurol.biomedcentral.com/articles/10.1186/s12883-019-1343-1

7 Arikunto, S. 2006. Metode Penelitian Kualitatif. Jakarta: Bumi Aksara

8 Romeo, D. M., Sini, F., Brogna, C., Albamonte, E., Ricci, D., \& Mercuri, E. (2016). Sex differences in cerebral palsy on neuromotor outcome: a critical review. Developmental Medicine and Child Neurology, 58(8), 809-813.

9. Nurfadilla, N,H., Gamayani,U., dan Nasution,D,T,G.,(2018), KOMORBIDITAS PADA PENYANDANG CEREBRAL

PALSY (CP) DI SEKOLAH LUAR BIASA (SLB),. Dharmakarya: Jurnal Aplikasi Ipteks untuk Masyarakat,Vol. 7, No. 2, Juni 2018: 90 - 96

10.Gabis, L. V., Tsubary, N. M., Leon, O., Ashkenasi, A., \& Shefer, S. (2015). Assessment of Abilities and Comorbidities in Children With Cerebral Palsy. Journal of Child Neurology, 30(12), 1640-1645

11. Cleves, Catalina., Lee, Jung Woo., Kabongo, L. Martin. (2011). Cerebral palsy. Medicina, 67(6 Pt 1), 586-592.

12. Minocha.P, Sitaraman.P, and Sachdeva P.(2017). Clinical Spectrum, Comorbidities, and Risk Factor Profile of Cerebral Palsy Children: A Prospective Study. J Pediatr Neurosci. 2017 Jan-Mar; 12(1): 15-18.

13.Hollung.J.S., Inger J Bakken,Torstein Vik,Stian Lydersen,Robert Wiik,Kari M Aaberg,Guro L Andersen, (2019)

Comorbidities in cerebral palsy: a patient registry study. Developmental Medicine \& Child Neurology(DMCN)

14 Minciu, I. (2012). Clinical correlations in cerebral palsy. Mædica, 7(4), 319-324.

15 Duke.R.E.,Tortey.E.,Okorei.U.,Min.J.kim.(2021)Pattern of comorbidities in school-aged children with cerebral palsy

in Cross River State, Nigeria. BMC Pediatrics volume 21, Article number: 165 (2021) 